\title{
Effectiveness of coproscopic concentration techniques
}

\author{
V. TAGLIORETTI*, N. H. SARDELLA, M. H. FUGASSA
}

\begin{abstract}
Laboratorio de Paleoparasitología y Arqueología Contextual, Facultad de Ciencias Exactas y Naturales, Universidad Nacional de Mar del Plata, Funes 3350, 7600, Mar del Plata, Buenos Aires, Argentina,

*E-mail: veronicataglioretti@hotmail.com
\end{abstract}

\begin{abstract}
Summary
The aim of the present study was to compare the effectiveness of the concentration techniques of flotation-centrifugation with zinc chloride (FZn) $(\delta=1.45)$ with the spontaneous sedimentation (SSed) and the sucrose flotation-centrifugation (FSuc) $(\delta=1.2)$ to recuperate gastrointestinal parasites from camelid fecal samples. The technique with more positive results for the detection of Nematodirus sp., Trichuris sp., strongyle-type eggs and Eimeria macusaniensis oocysts was the FZn. For Trichuris sp. and Eimeria macusaniensis, the higher coverglass counts were detected by FZn procedure. No significant differences were registered among centrifugation flotation techniques for Nematodirus spp. Coverglass count for strongyle-type eggs was significantly higher for FSuc than FZn $(p=0.0005)$ or SSed $(p=0.0005)$, being also significantly higher for FZn than for SSed $(p=0.008)$. FZn is a sensitive technique that allows the recovery of parasite elements with high density and it exerts low osmotic pressure avoiding parasite deformation.
\end{abstract}

Keywords: Concentration techniques; zinc chloride; parasite; camelid

\section{Introduction}

Stool examination must have high sensitivity, particularly when the parasitic material is present in low densities. Concentrations of parasites from herbivore faeces, including camelids, are often influenced by several factors that may contribute to the underestimation of gastrointestinal parasites; i.e. can be cited the amount of faeces processed for parasitological analysis, standardized at $2-5 \mathrm{~g}$ (Kaminsky, 2003) independently of the zoological origin of the faeces or the animal defaecation rate. Daily ungulate defecation rates are strongly more important than those of omnivores or of predators (Sánchez-Rojas \& Gallina, 2000; Orr et al., 2012), being the volume of ungulate fae- ces processed for parasitology examination often not representative. During sampling, abundant vegetal fibers are retained on meshes in the course of the screening, when some parasites could be also retained.

Common nematode parasites of domestic ruminants also infect South American camelids (SAC). However, they are frequently parasitized by several specific gastrointestinal parasites, as Lamanema chavezi, Eimeria macusaniensis, Nematodirus lamae and Trichuris tenuis, among others (Leguía 1991, 1999; Richard \& Bishop, 1991; Cafrune et al., 2001, 2009; Cebra \& Stang, 2008). Eggs of L. chavezi and oocysts of E. macusaniensis also exhibit particular features such as their large sizes and high specific gravity (Jarvinen, 1999; Cafrune et al., 2009). Cebra and Stang (2008) suggested that eggs of Trichuris sp. collected from camelids have high densities, and proper techniques must be performed for their diagnosis.

During the selection of coproparasitological concentration techniques, some factors must be taken into account. For flotation procedures, specific gravity of the flotation solution, viscosity, the volume of flotation solution employed, application of additional centrifugation step, duration and speed of centrifugation and the elapsed time, among others, must be considered (O'Grady \& Slocomb, 1980; Cringoli et al., 2004, 2010). Additionally important consideration is the selection of those procedures that causes the minimal egg distortion or destruction (O'Grady \& Slocomb, 1980; Quinn et al., 1980; Cringoli et al., 2004). Parasitological research on SAC usually utilizes flotation procedures with low specific gravities solutions $(\delta<1.3)$ (Leguía \& Casas, 1998; Jarvinen, 1999; Cafrune et al., 2001; Beldoménico et al., 2003; Cebra \& Stang, 2008) being probable that some parasites with high density are underscore, as it was suggested for E. macusaniensis or $L$. chavezi, among others (Jarvinen, 1999; Cafrune et al., 2001, 2009; Cebra \& Stang, 2008). Furthermore, reports evaluating the performance of common fecal diagnostic 
techniques on camelid feces are scarce (Jarvinen, 1999; Cebra \& Stang, 2008; Cafrune et al., 2009).

Zinc chloride flotation $(\delta=1.9)$ is also a technique widely used in palynological studies (Gray, 1965) and it was recently demonstrated its effectiveness to recover gastrointestinal parasites from human faeces (Taglioretti et al. 2012).

The aim of the present study was to compare the effectiveness of the concentration techniques by flotation with zinc chloride $(\delta=1.45)$ with two commonly used techniques in parasitology, the spontaneous sedimentation and the sucrose flotation $(\delta=1.2)$, to recuperate gastrointestinal parasites in current camelid fecal samples.

\section{Materials and methods}

\section{Studied materials}

A total of 20 fecal samples of South American camelids were examined for parasites. Four corresponded to Lama guanicoe collected from National Park Perito Moreno (NPPM), Santa Cruz; 11 to Lama lama collected from "Estancia La Reserva", Buenos Aires and the other 5 camelid faecal samples, 2 of Vicugna vicugna and 3 of $L$. lama, were sent from the laboratory from Instituto Nacional de Tecnología Agropecuaria, Estación Experimental Agropecuaria, Salta (National Institute of Agricultural Technology, Agricultural Experiment Station, Salta). Fecal samples proceeding from NPPM and "Estancia La Reserva" were collected from soil after animal defecation.

\section{Methodological protocol}

Each fecal sample was examined by 3 techniques: flotation-centrifugation with zinc chloride $(\delta=1.45)(\mathrm{FZn})$, sucrose flotation-centrifugation $(\delta=1.2)$ (FSuc) and spontaneous sedimentation (Lutz, 1919) (SSed). In order to achieve the volume enough to apply the techniques, 4 pellets were rehydrated in $50 \mathrm{ml}$ tubes with distilled water from each sample. The pellets were homogenized and the homogenate was screened through $300 \mu \mathrm{m}$ plastic mesh. The filtrate was first concentrated by gravitational sedimentation overnight in the refrigerator, and after, the supernatant was discarded.

With the aim to apply the different parasitological procedures, the concentrated filtrate obtained from the 4 pellets was homogenized and subsamples of $1 \mathrm{ml}$ of the homogenate were transferred to 3 centrifuge tubes of $15 \mathrm{ml}$. In the flotation-centrifugation procedures, the specific gravity of the solutions, the duration of the period of flotation and the possible distortion of parasites remains, were taken into account.

Flotation techniques were conducted as follows: the flotation medium was added to the centrifuge tube, leaving 1 $\mathrm{cm}$ below the rim of the tube. For FZn, a few drops of hydrochloric acid $10 \%$ were added to the sediment before the additions of the zinc chloride solution. The tube was centrifuged at 1000 r.p.m. by $5 \mathrm{~min}$. Then, the tube was completely filled with the flotation solution, and a coverglass was placed on the top of the tube, in contact with the fluid during $5 \mathrm{~min}$. After this period, the coverglass was removed and placed on a microscope slide for its examination. Once the first coverglass was removed, another one was placed on the top of the tube during $15 \mathrm{~min}$ more and the procedure was repeated for 30,60 and 80 min ( 5 slides for each technique were observed). For spontaneous sedimentation procedure, 5 slides were also observed.

Each slide was then examined by light microscopy (Zeiss Primo Star) under 10X magnifications and parasite identifications and measurements were done under 40X magnifications. Images were registered by digital camera and edited by Image J $1.44 \mathrm{p}$. It was also noted whether parasites remains were deformed, collapsed or distorted. Number of eggs and cysts which floated and adhered to a coverglass were counted and the coverglass counts were also registered for spontaneous sedimentation procedure.

\section{Statistical analysis}

The proportions of samples that yielded positive results for each parasite were compared among the 3 procedures by use of the Cochrane Q test. The percent of agreement (PA) among methods was also calculated according to Gordis (2000).

To investigate differences in eggs and cysts counts, positive results for each parasite were compared among methods using the Friedman repeated-measures on ranks. The Wilcoxon signed rank test with Bonferroni correction was used for pairwise comparisons. All comparisons were considered significant at values of $p<0.05$. In cases where significant differences were detected by pairwise comparisons, Wilcoxon signed rank tests (alternative hypothesis: less) were also applied to detected which technique recovered more eggs at a significant level of $p=0.05$.

Coverglass counts were done in different flotation periods for both flotation-centrifugation techniques, to assess whether the floating period could influence on the number of eggs or cysts recovered, and to estimate the optimal floating period in which most parasites can be found. Furthermore, total coverglass count was computed as the sum of coverglass counts for each flotation period of all positive samples for each procedure.

\section{Results}

Ability to detect positives samples among procedures

Of the 20 fecal samples examined, strongyle- type eggs were found in 12 samples, Nematodirus spp. in 13 samples, Trichuris spp. in 9 samples and E. macusaniensis in 4 samples for at least one of the three procedures.

The proportion of positive samples according to the method used was significantly different for Nematodirus sp., Trichuris sp. and strongyle-type eggs and also for $E$. macusaniensis oocysts (Table 1). In all cases, the technique with more positive results for the detection of parasites studied was the flotation-centrifugation with zinc clorhidric solution (FZn), being this the most sensitive procedure (Table 1). 
Table 1. Number $\left(\mathrm{N}^{\circ}\right)$ and proportion (\%) of positive samples resulting from the 3 techniques

\begin{tabular}{|c|c|c|c|c|}
\hline \multirow[b]{2}{*}{ Parasite } & \multicolumn{3}{|c|}{ Technique } & \multirow[b]{2}{*}{ Total } \\
\hline & $\begin{array}{c}\text { FSuc } \\
N^{\circ}(\%)\end{array}$ & $\begin{array}{c}\text { FZn } \\
\mathrm{N}^{\circ}(\%)\end{array}$ & $\begin{array}{c}\text { SSed } \\
\mathrm{N}^{\circ}(\%)\end{array}$ & \\
\hline E. macusaniensis ${ }^{\text {a }}$ & $1(25)$ & $4(100)$ & $0(0)$ & 4 \\
\hline Trichuris sp. ${ }^{\text {a }}$ & $4(44.4)$ & $8(88.8)$ & $5(55.5)$ & 9 \\
\hline Nematodirus sp. ${ }^{\text {a }}$ & $10(76.92)$ & $11(84.6)$ & $2(15.4)$ & 13 \\
\hline Strongylus-type ${ }^{\text {a }}$ & $11(91.66)$ & $12(100)$ & $6(50)$ & 12 \\
\hline
\end{tabular}

Of the 12 samples positive for strongyle-type eggs, 6 were positive by the all 3 methods $(\mathrm{PA}=50 \%), 4$ were positive by the 2 flotation techniques $(\mathrm{PA}=33.3 \%), 2$ only by $\mathrm{FZn}$ and 1 only by FSuc. No positive samples by the SSed and negative by the other techniques were found. The percentage of agreement for Nematodirus sp. eggs by the 3 techniques was around $15 \%(2 / 13), 1$ sample was positive only by FSuc and 3 only by FZn, for both flotation techniques the PA was around $69 \%$ (9/13). Positive samples for sedimentation were in all cases positive by the other 2 techniques. For Trichuris sp. eggs, the PA for the 3 procedures was around $44 \%$ (4/9), 4 positive samples were detected by FZn only, 1 by SSed and all samples positive by FSuc (4) were also positive by the other procedures. Of the 4 samples positive for E. macusaniensis oocysts, none was positive for SSed, and the PA for both flotation procedures was around $25 \%(1 / 4)$.

Coverglass counts among procedures

There were significant differences among the three procedures in the total coverglass count for Nematodirus sp. (Friedman chi-squared $=14.7568, \mathrm{p}=0.0006246)$, Trich $u$ ris $\mathrm{sp}$. (Friedman chi-squared $=14, \mathrm{p}=0.0009119$ ), strongyle-type eggs (Friedman chi-squared $=19.4634, \mathrm{df}=2$, pvalue $=5.937 \mathrm{e}-05)$ and $E$. macusaniensis oocysts $(\mathrm{p}=0.02)$. Pairwise comparisons are shown in Table 2. For Trichuris sp. eggs and E. macusaniensis oocysts, the higher coverglass count was detected by FZn procedure, being for Trichuris sp. eggs significantly higher than from the other procedures $(\mathrm{p}<0.05$ in both cases). The FSuc was the technique that more strongyle-type and Nematodirus sp. eggs recovered. Nevertheless, no significant differences were detected among centrifugation flotation techniques for Nematodirus spp. eggs (Table 2). Cover- glass count for strongyle-type eggs was significantly higher for FSuc than FZn $(p=0.0005)$ or SSed $(\mathrm{p}=0.0005)$, being also significantly higher for FZn than for SSed $(p=0.008)$.

Coverglass counts for each flotation period

Total coverglass counts for different flotation periods for both flotation-centrifugation procedures are shown in Table $3 ; 60 \%$ of the eggs of the parasites studied were recovered between 5 and 30 minutes of flotation, independently of the centrifugation-flotation technique employed; $100 \%$ of the oocysts of E. macusaniensis were also found at this flotation period by FZn procedure, but the only oocyst registered by FSuc technique was at $80 \mathrm{~min}$ of the flotation period. Neither the number of eggs/oocysts nor the parasitic diversity increased with the increase of the flotation period before $30 \mathrm{~min}$ (Table 3 ).

Neither distortion nor alteration of morphology of organisms was observed by the application of the flotationcentrifugation techniques.

\section{Discussion}

Spontaneous sedimentation was the less sensitive technique to detect SAC gastrointestinal parasites, except for eggs of Trichuris sp. The centrifugation zinc chloride flotation technique yielded the highest proportion of positive results for all parasites and also the highest egg/oocyst counts for Trichuris sp. and for E. macusaniensis. This is what it was expected, since Trichuris sp. eggs, found in camelids, and E. macusaniensis oocysts are high density structures (Jarvinen, 1999; Cebra \& Stang, 2008; Cafrune et al., 2009).

Table 2. Pairwise comparisons of coverglass counts among procedures (only positive samples were taken into account)

\section{Parasite}

\begin{tabular}{lcccccccc}
\hline \multirow{2}{*}{ Technique } & \multicolumn{2}{c}{ E. macusaniensis } & \multicolumn{2}{c}{ Trichuris sp. } & \multicolumn{2}{c}{ Nematodirus sp. } & \multicolumn{2}{c}{ Strongyle-type } \\
& FSuc & FZn & FSuc & FZn & FSuc & FZn & FSuc & FZn \\
\hline FSuc & - & NS & - & SD & - & NS & - & SD \\
FZn & NS & - & SD & - & NS & - & SD & - \\
SSed & NS & NS & NS & SD & SD & SD & SD & SD \\
\hline
\end{tabular}


Table 3. Total coverglass counts for different flotation period among flotation-centrifugation procedures

\begin{tabular}{lcccccccccc}
\hline & \multicolumn{1}{c}{ Total coverglass counts by time period } \\
\cline { 2 - 11 } Parasite & \multicolumn{1}{c}{ FSuc (min) } & \multicolumn{7}{c}{ FZn (min) } \\
& $\mathbf{5}$ & $\mathbf{1 5}$ & $\mathbf{3 0}$ & $\mathbf{6 0}$ & $\mathbf{8 0}$ & $\mathbf{5}$ & $\mathbf{1 5}$ & $\mathbf{3 0}$ & $\mathbf{6 0}$ & $\mathbf{8 0}$ \\
\cline { 2 - 11 } m macusaniensis & - & - & - & - & 1 & 6 & 3 & 3 & - & - \\
Trichuris sp. & 28 & 5 & 9 & 4 & 14 & 13 & 37 & 39 & 22 & 30 \\
Nematodirus sp. & 49 & 15 & - & - & - & 29 & 5 & 2 & 3 & 2 \\
Strongyle-type & 473 & 214 & 631 & 254 & 48 & 129 & 36 & 27 & 28 & 40 \\
\hline
\end{tabular}

Studies carried out by Cebra and Stang (2008) suggested that a high specific gravity solution may improve Nematodirus spp. egg counts. Nevertheless, the highest counts of Nematodirus spp. in the present study were reported by the centrifugation-sucrose flotation technique, although differences with zinc chloride solution were no significant. This is argued with Grady and Slocomb (1979) who verified that Nematodirus spp. eggs floated equally well in nitrate solutions with specific gravity ranging from 1.22 to1.38.

The implementation of the centrifugation step improves the recovery of strongyle type eggs as it was reported for other flotation techniques with different media (Zajac et al., 2002; Cebra \& Stang, 2008). In the present study, a centrifugation step was added to both flotation procedures, so differences in strongyle egg counts among flotation techniques are not solely dependent on specific gravities of solutions as it was proposed by other authors (Quinn et al., 1980; Cringoli et al., 2004), being probably that differences in the solution characteristics, like viscosity and/or osmotic pressure may be influencing eggs floating capacity.

Additionally, since strongyle type eggs have thin shells, the addition of drops of hydrochloric acid to the tube before the addition of the zinc chloride solution, in the case of the centrifugation in the zinc chloride flotation, could also destroy or modify egg shells, inhibiting their suspensions. Osmotic pressures increase as the density of the solution increases, and it is possible that osmotic pressure that exerts zinc chloride on these eggs is higher than those of the sucrose solution, altering the eggshells. Despite this, neither egg distortions nor alterations were observed at any elapsed time.

The elapsed time was taken into account, since a too early count can affect those slow-rising parasites, and a too late one may allow parasites to become distorted, particularly those with thin walls, like strongyle type eggs (Bowman et al., 2003, Cebra \& Stang, 2008). However, additional elapsed time (up to $30 \mathrm{~min}$.) did not increase egg or cyst counts as it was reported for Trichuris sp., Capillaria sp., strongyle type eggs and E. macusaniensis oocysts by the application of centrifugation sucrose flotation procedure (Cebra \& Stang, 2008). E. macusaniensis was the exception, since the only oocyst detected by the centrifugationsucrose flotation method was at $80 \mathrm{~min}$.

Although during the performance of the centrifugation zinc chloride flotation there appeared increased amounts of fecal debris floating than in the centrifugation sucrose flotation technique, the amount of debris was less than that observed in slides processed by spontaneous sedimentation, and the recognition of eggs and cysts under the coverglass could be done successfully being the reading time significantly less.

The present study highlights the centrifugation zinc chloride flotation technique as a sensitive method to recover and to identify SAC gastrointestinal parasites, allowing the recovery of parasite elements of high density and exerting low osmotic pressure avoiding parasite deformation.

However, here it is proposed that techniques may be used in series, since although FZn had better diagnostic sensitivity compared with spontaneous sedimentation and centrifugation sucrose flotation, it was less effective in the recovery rate of strongyle-type eggs compared with sucrose solutions. Efforts to improve egg/cyst recovery rates by the implementation of a high density solution and likely the additions of a centrifugation step in the flotation procedures were successful, except for strongyle-type eggs.

\section{Acknowledgements}

We thank to the National Parks Administration, Patagonia Regional Delegation; to Lic. Mercedes Cafrune, from the National Institute of Agricultural Technology, Agricultural Experiment Station, Salta and to Sandra Escobar from "Estancia La Reserva".

The present study was funded by grants from CONICET (PIP 090/11), UNMDP (EXA590/12), and FONCyT (PICT 1576/07).

\section{References}

Beldoménico, P. M., Uhart, M., Bono, M. F., Marull, C., BALDI, R., Peralta, J. L. (2003): Internal parasites of free-ranging guanacos from Patagonia. Vet. Parasitol., 118: 71 - 77. DOI: 10.1016/j.vetpar.2003.09.008

Bowman, D. D., LynN R. C., Eberhard M. L. (2003): Diagnostic parasitology. In: BowmAN, D. D., LYNN R. C., EBERHARD M. L. (Eds) Georgi's parasitology for veterinarians. St Louis: WB Saunders Co, pp. $286-358$

CAfrune, M. M, Aguirre, D. H., Richard, L. G. (2001): First report of Lamanema chavezi (Nematoda: Trichostrongyloidea) in llamas (Lama glama) from Argentina. Vet. Parasitol., 97: 165 - 168. DOI: 10.1016/S0304-4017 (01)00379-X 
Cafrune, M. M., Marín, R. E., Rigalt, F. A., Romero, S. R., Aguirre, D. H. (2009): Prevalence of Eimeria macusaniensis and Eimeria ivitaensis in South American camelids of Northwest Argentina. Vet. Parasitol., 162: 338 - 341. DOI: 10.1016/j.vetpar.2009.03.006

Cebra, C. K., Stang, B. V. (2008): Comparison of methods to detect gastrointestinal parasites in llamas and alpacas. J. Am. Vet. Med. Assoc., 232: 733 - 741. DOI: $10.2460 /$ javma.232.5.733

CRingoli, G., Rinaldi, L., Veneziano, V., CAPelli, G., SCALA, A. (2004): The influence of flotation solution, sample dilution and the choice of McMaster slide area (volume) on the reliability of the McMaster technique in estimating the faecal egg counts of gastrointestinal strongyles and Dicrocoelium dendriticum in sheep. Vet. Parasitol., 123: 121 - 131. DOI: 10.1016/j.vetpar.2004.05.021

CRingoli, G., RinAldi, L., MAURELLI, M. L., UtzingeR, J. (2010): FLOTAC: new multivalent techniques for qualitative and quantitative copromicroscopic diagnosis of parasites in animals and humans. Nature Protocols, 5: $503-$ 515. DOI:10.1038/nprot.2009.235

GORDIS, L. (2000): Assessing the validity and reliability of diagnostic and screening tests. In: Epidemiology. $2^{\text {nd }}$ Edition, W.B. Saunders Pennsylvania, pp. $63-81$

GRAY, J. (1965): Extraction techniques. In: BERNHARD, K. AND RAUP, D. (Eds) Handbook of Paleontological Techniques. Freeman, San Francisco \& London, pp. 530 - 587

JARVInEN, J. A. (1999). Prevalence of Eimeria macusaniensis (Apicomplexa: Eimeriidae) in Midwestern Lama spp. J. Parasitol., 85: 373 - 376. DOI: 10.2307/3285651

KAMINSKY, R. G. (2003): Manual de parasitología. Métodos para laboratorios de atención primaria de salud. OPS, OMS, UNAH, $141 \mathrm{pp}$.

LEguíA, G. P. (1991): The epidemiology and economic impact of llama parasites. Parasitol. Today, 7: $54-56$. DOI: 10.1016/0169-4758(91)90190-Y

RECEIVED SEPTEMBER 30, 2013
Leguía, G. P., CASAS, E. (1999): Enfermedades parasitarias y atlas parasitológico de camélidos sudamericanos. Ed. De Mar. Lima, pp. 191

Leguía, G. P., CASAS, E. (1998): Eimeria ivitaensis n. sp. (Protozoa: Eimeriidae) en alpacas (Lama pacos). Rev. Per. Parasitol., 13: 59 - 61

O'Grady, M. R., Slocombe, J. O. D. (1980): An investigation of variables in a fecal flotation technique. Can. J. Comp. Med., 44: 148 - 154

OrR, R. J., Griffith, B. A., Champion, R. A., CoOK, J. E. (2012): Defaecation and urination behaviour in beef cattle grazing semi-natural grassland. Appl. Anim. Behav. Sci., 139: 18 - 25. DOI: 10.1016/j.applanim.2012.03.013

Quinn, R., Smith, H. V., Bruce, R. G., Girdwood, R. W. A. (1980): Studies on the incidence of Toxocara and Toxascaris spp. ova in the environment. 1. A comparison of flotation procedures for recovering Toxocara spp. ova from soil. J. Hyg. Cambridge, 84: 83 - 89

RICKARD, L., BISHOP, J. (1991): Redescription of Trichuris tenuis, Chandler, 1930, from llamas (Lama glama) in Oregon with a key to the species of Trichuris present in North American ruminants. J. Parasitol., 77: 70 - 75

SÁnchez-Rojas, G., GallinA, S. (2000): Mule deer (Odocoileus hemionus) density in a landscape element of the Chihuahuan Desert, Mexico. J. Arid. Environ. 44: 357 - 368. DOI: 10.1006/jare.1999.0605

Taglioretti V., Fugassa, M. H., MaYo IÑIgUeZ A., SARDELla N. H. (2012): Evaluación de la eficacia de la flotación con cloruro de zinc como método de enriquecimiento para la recuperación de huevos de enteroparásitos. Rev. Arg. Parasitol., 1: 164

ZAJAC, A. M., JoHnSON, J., KING, S. E. (2002): Evaluation of the importance of centrifugation as a component of zinc sulfate fecal flotation examinations. J. Am. Anim. Hosp. Assoc., 38: $221-224$

ACCEPTED JULy 7, 2014 